\title{
Geochemiczno-mineralogiczne badania zawartości pierwiastków rzadkich i towarzyszących w obrębie mineralizacji kasyterytowo-siarczkowej w lupkowym paśmie Starej Kamienicy w Sudetach Zachodnich - wyniki wstępne
}

\author{
Rafał Małek $^{1}$, Stanisław Z. Mikulski ${ }^{1}$
}

\begin{abstract}
Geochemical-mineralogical research of the rare and associated element concentrations within cassiterite-sulphide mineralization in the Stara Kamienica schist belt in the Western Sudetes - preliminary results. Prz. Geol., 67: 179-182; doi: 10.7306/2019.14

A b s tr a c t. The main task of research was to quantitatively and qualitatively identify rare and associated elements that occur within a cassiterite-sulphide mineralization zone hosted Precambrian - Lower Paleozoic metamorphic rocks in the Stara Kamienica schist belt making up the part of the Izera-Karkonosze Massif. Over 70 samples from archive boreholes and abandoned Sn-ore mines were examined using modern methods like portable pXRF, geochemical analysis (ICP-MS, WD-XRF, GF-AAS), polarizing microscopy, electron microprobe analysis (EMPA) and scaning electron microscopy with EDS system (SEM-EDS). Preliminary results show interesting concentrations of associated elements such as $\mathrm{Zn}$ (max 0.56\%), Pb (max 0.7\%), $\mathrm{Cu}$ (max 0.33\%), As (max 0.55\%), and some rare elements like In, Re, $\mathrm{Nb}, \mathrm{Co}, \mathrm{Bi}, \mathrm{Pt}, \mathrm{V}, \mathrm{La}$ and $\mathrm{Ce}$.
\end{abstract}

Keywords: rare elements, cassiterite, sulfides, ore mineralization, ore deposit, Sudetes

Przedmiotem badań były próbki pobrane $\mathrm{z}$ rdzeni wiertniczych $\mathrm{z}$ rejonu udokumentowanych złóż cyny w Krobicy i Gierczynie, z udostępnionych turystycznie sztolni św. Jana i św. Leopolda w Krobicy oraz z kamieniołomu łupków łyszczykowych w Gierczynie w Sudetach. Prace badawczo-analityczne zostały wykonane w Państwowym Instytucie Geologicznym - Państwowym Instytucie Ba- dawczym (PIG-PIB), a sfinansowane ze środków Narodowego Funduszu Ochrony Środowiska i Gospodarki Wodnej (NFOŚiGW) (Mikulski i in., 2018a).

Rudy kasyterytowe cyny występują w dolnopaleozoicznym paśmie łupkowym Starej Kamienicy, stanowiącym część masywu karkonosko-izerskiego (północnej okrywy waryscyjskiego granitoidu karkonoskiego) w Sudetach

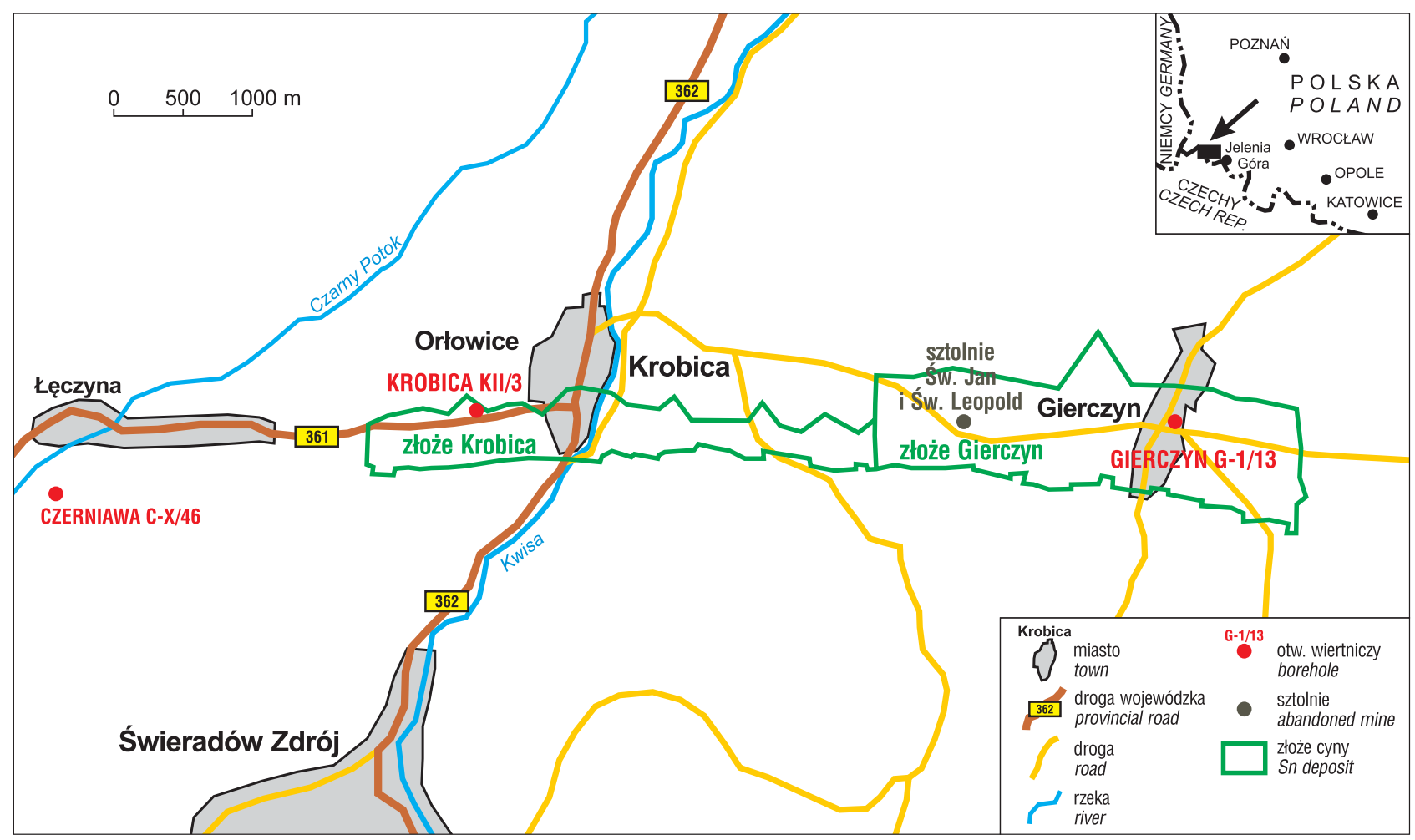

Ryc. 1. Lokalizacja miejsc opróbowania w strefie złóż cyny w Krobicy i Gierczynie w paśmie łupkowym Starej Kamienicy w Sudetach Zachodnich

Fig. 1. Location of the sampling sites within the Krobica and Gierczyn tin deposits in the Stara Kamienica schist belt in the Western Sudetes

${ }^{1}$ Państwowy Instytut Geologiczny - Państwowy Instytut Badawczy, ul. Rakowiecka 4, 00-975 Warszawa; rmal@pgi.gov.pl, stanislaw.mikulski@pgi.gov.pl 
Zachodnich (ryc. 1) (Szałamacha, Szałamacha, 1974). Łupki łyszczykowe, zawierające mineralizację kasyterytowo-siarczkową, są skałami drobnoziarnistymi, o jasnoszarej barwie (często z zielonkawym odcieniem), z wyraźnie widoczną foliacją i laminacją (Michniewicz i in., 2006). Zawarta w nich mineralizacja powstała w skutek działalności roztworów hydrotermalnych, które przestrzennie, czasowo i genetycznie były bezpośrednio łączone $\mathrm{z}$ intruzją granitoidu karkonoskiego (Wiszniewska, 1984) lub z wcześniejszym rozwojem procesów magmowo-metamorficznym (Michniewicz i in., 2006).

Celem badań była identyfikacja oraz charakterystyka pierwiastków rzadkich i towarzyszących mineralizacji kasyterytowo-siarczkowej. Pierwiastki towarzyszące w rudach kasyterytowych są reprezentowane przez siarczki metali takich jak cynk, ołów czy miedź. Występują one lokalnie w podwyższonych koncentracjach, które mogą stanowić dodatkową wartość ekonomiczną złóż (Mikulski i in., 2018a, b). Do pierwiastków rzadkich współwystępujących w rudach siarczkowo-kasyterytowych autorzy zaliczaja takie, które z reguły nie tworzą własnych faz mineralnych, lecz występują głównie w postaci różnych domieszek w minerałach kruszcowych i/lub akcesorycznych.

\section{ZAKRES I METODYKA BADAŃ}

Dotychczas pobrano ok. 70 próbek, z czego większość pochodziła $z$ otworów wiertniczych G-1/13, KII/3 oraz $\mathrm{C}-\mathrm{X} / 46$. Braki w zachowanych rdzeniach otworów wiertniczych wykonanych w latach 70. XX w. umożliwiły jedynie opróbowanie stref okołobilansowych, a tylko kilka próbek pochodziło z interwałów bilansowych tych 3 otworów.

W celu wyznaczenia miejsc poboru próbek w profilach rdzeni oraz prześledzenia koncentracji pierwiastków w wyznaczonych interwałach posłużono się przenośnym spektrometrem pXRF Delta Premium firmy Olympus. Przedmiotem badań geochemicznych (metodami ICP-MS, WD-XRF oraz GF-ASS) były 42 próbki, w których oznaczono ponad 50 pierwiastków. Dodatkowo wykonano ok. 50 preparatów mikroskopowych, na których przeprowadzono szczegółowe badania petrograficzno-kruszcowe na mikroskopie polaryzacyjnym Nikon Eclipse LV100 POL z oprogramowaniem Nis-Elements oraz na części preparatów również badania jakościowo-ilościowe w mikroobszarze na mikrosondzie elektronowej Cameca SX-100 ze spektrometrem WDS, poprzedzone obserwacjami na skaningowym mikroskopie elektronowym Leo-1430 (ZEISS) z detektorem WDS.

\section{WYNIKI BADAŃ \\ GEOCHEMICZNO-MINERALOGICZNYCH}

Wykonano ok. 160 pomiarów koncentracji pierwiastków spektrometrem pXRF Delta Premium na archiwalnych rdzeniach wiertniczych $\mathrm{w}$ interwałach średnio co ok. $0,5 \mathrm{~m}$ oraz ok. 100 pomiarów w historycznych sztolniach św. Jana i św. Leopolda w Krobicy. Punktowe pomiary wykazały interesujące zawartości niektórych pierwiastków, m.in.: Sn w przedziale $8( \pm 2)-148( \pm 4)$ ppm; V: $4( \pm 4)-820( \pm 12)$ ppm; Cu: 9( \pm 3$)$ ppm-0,53\% ( \pm 33 ppm); Ti: $51( \pm 5)$ ppm-2,54\% ( \pm 316 ppm); Cr: $9( \pm 2)-828( \pm 16)$ ppm; As: $3( \pm 0,8)$ ppm2,28\% ( \pm 146 ppm); Au: 9 ( \pm 3$)-992( \pm 27)$ ppm; Rb: $2( \pm 0,6)$ $359( \pm 4)$ ppm. Porównanie średnich wartości niektórych

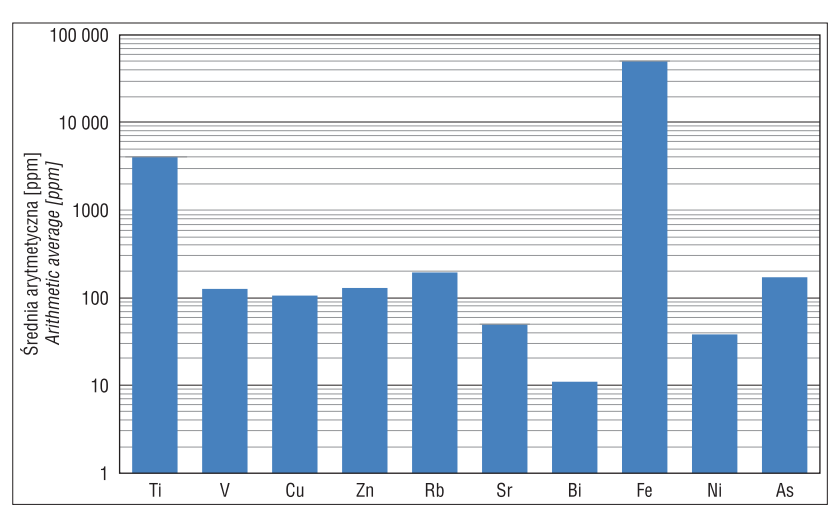

Ryc. 2. Porównanie średnich arytmetycznych zawartości niektórych pierwiastków (w ppm) pomierzone w otworach wiertniczych Krobica G-1/13 i Krobica KII/3 przy użyciu pXRF

Fig. 2. Comparison of arithmetic averages of some elements content (in ppm) measured by pXRF in the Krobica G-1/13 and Krobica KII/3 boreholes

pierwiastków pomierzonych spektrometrem pXRF przedstawia rycina 2.

W przeprowadzonych badaniach geochemicznych (XRF, ICP-MS, GFASS) zidentyfikowano ponad 50 pierwiastków, wśród których znaczną ilość stanowią pierwiastki rzadkie oraz takie, które zostały uznane za krytyczne (deficytowe) dla funkcjonowania gospodarki Unii Europejskiej (COM, 2017). Są to m.in.: Sb, Bi, Co, Ga, Ge, Hf, In, Mg (MgO), $\mathrm{Nb}, \mathrm{P}\left(\mathrm{P}_{2} \mathrm{O}_{5}\right), \mathrm{Sc}, \mathrm{W}, \mathrm{V}, \mathrm{Pd}, \mathrm{Pt}$ oraz REE i Y. Analizy geochemiczne wykazały, że w próbkach są zawarte podwyższone koncentracje pierwiastków towarzyszących mineralizacji kasyterytowej, takie jak: $\mathrm{Zn}(\max .0,56 \%), \mathrm{Pb}$ (max. $0,7 \%), \mathrm{Cu}(\max .0,33 \%)$ i As $(\max .0,55 \%)$, oraz niektórych pierwiastków rzadkich, tj. In, Re, Nb, Co, Bi, Pt, V oraz La i Ce. Interesujące średnie geometryczne koncentracje (dla $n=42)$ wykazują m.in.: In -0,41 ppm, Nb-10,6 ppm, $\mathrm{Re}-0,46 \mathrm{ppm}, \mathrm{Pt}-46 \mathrm{ppm}$. Wzbogacenie w niektóre pierwiastki rzadkie w stosunku do ich średnich zawartości w skorupie ziemskiej zaprezentowano na rycinie 3.

Zawartość Sn w większości próbek kształtuje się na poziomie poniżej $0,1 \%$. Koncentracje cyny wykazują dodatnią korelację z niektórymi pierwiastkami rzadkimi, np. z galem (współczynnik korelacji $r=0,48$; ryc. 4A) i bizmutem $(r=0,51$; ryc. $4 \mathrm{~B})$.

Obserwacje na mikroskopie polaryzacyjnym pozwoliły na określenie minerałów skałotwórczych i kruszcowych oraz określenie wzajemnych relacji między nimi. Głównymi rozpoznanymi minerałami skałotwórczymi są kwarc, muskowit, biotyt, chloryt oraz podrzędnie chlorytoid, albit, staurolit i granaty. Minerały generalnie zgrupowane są w laminy łyszczykowe i laminy kwarcowe (kwarcowo-skaleniowe). Dosyć powszechnie występujące porfiroblasty granatów średnicy do $5 \mathrm{~mm}$ wskazują na strukturę granolepidoblastyczną. W obrębie lamin łyszczykowych (głównie takich z przewaga chlorytu) występują charakterystyczne groniaste nagromadzenia kasyterytu (ryc. 5A). Minerały kruszcowe obserwowane w świetle odbitym tworzą agregaty różnej wielkości, wzajemnie się przerastające i występujące w postaci wrostków w innych minerałach. Najczęściej wykazują postać ksenomorficzną lub hipautomorficzną. Głównymi minerałami kruszcowymi obok kasyterytu są: pirotyn, piryt, chalkopiryt, sfaleryt, bizmutynit oraz ilmenit i rutyl (ryc. 5B, C). 


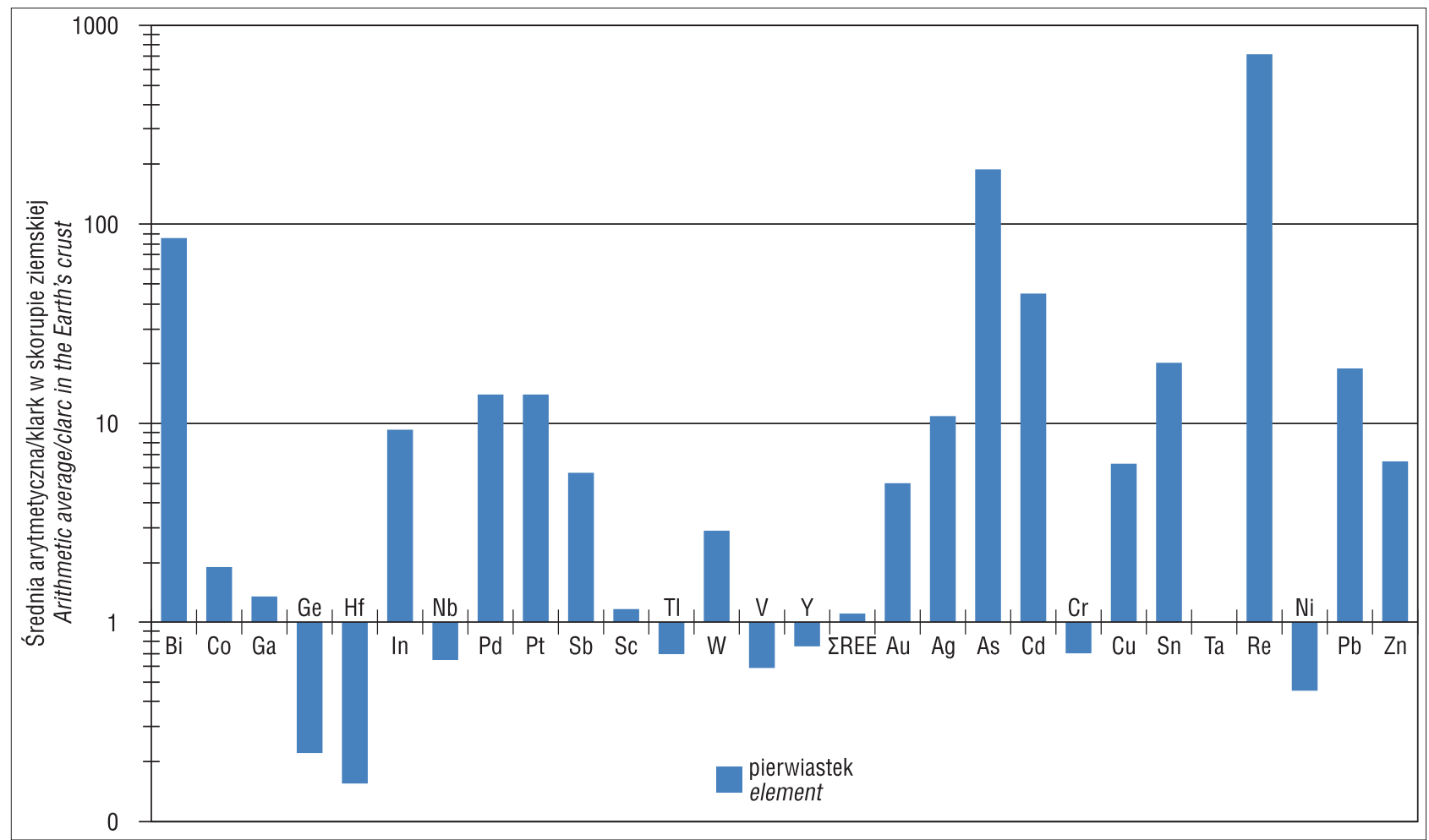

Ryc. 3. Porównanie średniej arytmetycznej zawartości pierwiastków w próbkach $(n=42) \mathrm{w}$ stosunku do ich średnich zawartości (klark) w skorupie ziemskiej (klarki skompilowane wg Taylora (1964) oraz Paulo i Krzaka (2015)

Fig. 3. Comparison of the arithmetic average of content in samples $(n=42)$ relative to average contents (Clarc) in the Earth's crust (Taylor, 1964; Paulo, Krzak, 2015)
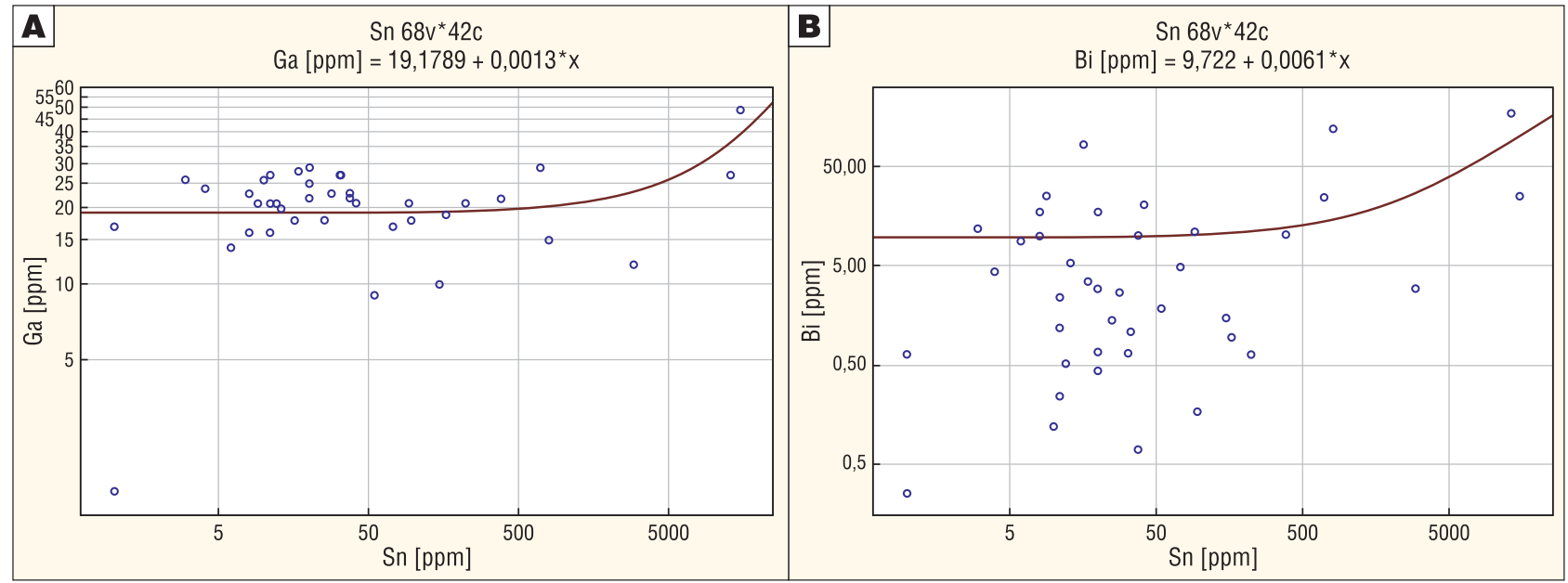

Ryc. 4. Wykresy rozrzutu z zaznaczonymi liniami trendu w próbkach z mineralizacją kasyterytowo-siarczkową. A-cyny (Sn) względem galu (Ga), B - cyny (Sn) względem bizmutu (Bi)

Fig. 4. Scatter plots with marked trend lines in cassiterite-sulphide samples. A $-\mathrm{Sn} v s$. Ga, B $-\mathrm{Sn} v s$. Bi

Analizy ilościowe próbek wykonane na mikrosondzie elektronowej umożliwiły identyfikację minerałów akcesorycznych (ryc. 5B, D) oraz określenie składu chemicznego poszczególnych minerałów (za pomocą spektrometru WDS i detektora EDS). Rozpoznano następujące nośniki pierwiastków rzadkich i towarzyszących - kasyteryt: $\mathrm{W}$ na poziomie max. $0,8 \%$ wag. oraz Ce max. $0,2 \%$ wag.; pirotyn: Ni (max. 0,56\% wag.), Co (max. 0,29\% wag.), Au (max. $0,14 \%$ wag.); chalkopiryt: $\mathrm{Bi}$ (max. $2,2 \%$ wag.), As (max. $4,35 \%$ wag.), $\mathrm{Ni}$ (max. $0,59 \%$ wag.), $\mathrm{Co}$ (max. $0,4 \%$ wag.), $\mathrm{Au}$ (max. $0,15 \%$ wag.); piryt: Ni (max. $0,66 \%$ wag.), Co (max. 0,35\% wag.), Au (max. 0,13\% wag.); arsenopiryt: $\mathrm{Sb}$ (max. 0,86\% wag.), Bi (max. 9,13\% wag.), Se (max.
1,26\% wag.), Ni (max. $1,64 \%$ wag.), Co max. $9,08 \%$ wag.), $\mathrm{Au}$ (max. 0,2\% wag.); sfaleryt: $\mathrm{Cd}$ (max. 0,67\% wag.); bizmut rodzimy i bizmutynit: $\mathrm{Te}$ (max. 0,39\% wag.), $\mathrm{Sb}$ (max. 2,73\% wag.), Se (max. $0,71 \%$ wag.), As (max. $2,74 \%$ wag.), $\mathrm{Ni}$ (max. 0,83\% wag.), Co (max. 0,63\% wag.), Au (max. $8,23 \%$ wag.). Ponadto zidentyfikowano akcesoryczne minerały kruszcowe zawierające interesujące pierwiastki metaliczne, takie jak: kobaltyn (Co max. 34,7\% wag.), costibit (Co max. 24,5\% wag.), gersdorfiit (Ni max. 26,63\% wag., Co max. $11,22 \%$ wag.), hessyt (Te max. $41,3 \%$ wag., Ag max. 61,3\% wag.), sakuraiit (In max. 19,1\% wag.) oraz ullmannit ( $\mathrm{Sb}$ max. 53,0\% wag., Bi max. 23,38\% wag.). 


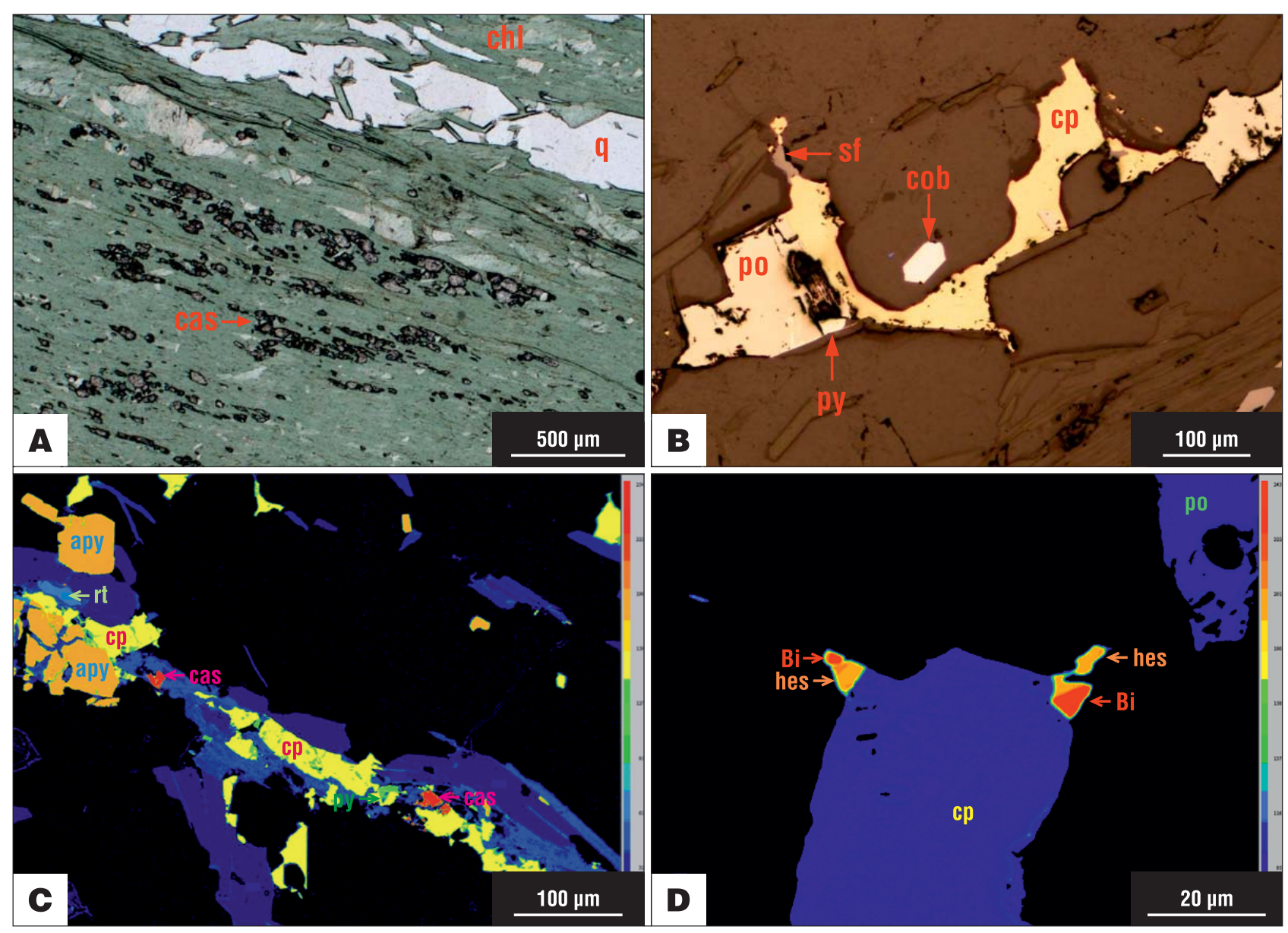

Ryc. 5. A - charakterystyczne wystapienie kasyterytu (cas) w obrębie laminy chlorytowej (chl) w łupku łyszczykowo-kwarcowym (q), światło przechodzące, NII; B - agregat siarczkowy z kobaltynem (cob) w laminie kwarcowej, światło odbite, NII; C - agregat siarczkowy z kasyterytem w laminie chlorytowej, obraz BSE; D - agregat siarczkowy z minerałem akcesorycznym - hessytem (hes), obraz BSE. Objaśnienie symboli: py - piryt, po - pirotyn, cp - chalkopiryt, sf - sfaleryt, apy - arsenopiryt, Bi - bizmut rodzimy

Fig. 5. A - characteristic cassiterite (cas) occurrence within a chlorite (chl) lamina in quartz (q) mica schist, transmitted light, NII; B - sulphide aggregate with cobaltite (cob) within a quartz lamina, reflected light, NII; C - sulphide aggregate with cassiterite within a chlorite lamina, BSE image; D - sulphide aggregate with an accessory mineral - hessite (hes). Symbol explanations: py - pyrite, po pyrrohite, $\mathrm{cp}$ - chalcopyrite, $\mathrm{sf}$ - sphalerite, apy - arsenopyrite, $\mathrm{Bi}$ - native bismuth

\section{WNIOSKI}

W zbadanych próbkach z mineralizacją kasyterytowo-siarczkową pochodzących z obszaru dawnego kopalnictwa i udokumentowanych złóż rud cyny w Krobicy i Gierczynie w Sudetach Zachodnich zidentyfikowano występowanie ponad 50 pierwiastków głównych i śladowych.

Głównym nośnikiem cyny jest kasyteryt, któremu w próbkach powszechnie towarzyszy mineralizacja siarczkowa. W próbkach stwierdzono podwyższone koncentracje pierwiastków towarzyszących $-\mathrm{Zn}, \mathrm{Pb}, \mathrm{Cu}$ i As oraz pierwiastków rzadkich (In, Re, Ni, Co, Bi, PGE, V, La oraz Ce). Cyna wykazuje pozytywną korelację z niektórymi pierwiastkami rzadkimi, np. $\mathrm{z}$ bizmutem i galem.

Najważniejszymi nośnikami pierwiastków rzadkich są siarczki, tj. piryt, chalkopiryt, pirotyn, sfaleryt, arsenopiryt czy bizmutynit.

Prace badawczo-analityczne zostały wykonane w Państwowym Instytucie Geologicznym - Państwowym Instytucie Badawczym, a sfinansowane ze środków Narodowego Funduszu Ochrony Środowiska i Gospodarki Wodnej zgodnie z umową nr 506/2015 (poz. pl. 22.6705.1501.01.1).

\section{LITERATURA}

COM 2017 - Komunikat komisji do Parlamentu Europejskiego, Rady, Europejskiego Komitetu Ekonomiczno-Społecznego i Komitetu Regionów w sprawie wykazu surowców krytycznych dla UE 2017. Komisja Europejska, Bruksela, 13.09.2017 r.

MICHNIEWICZ M., BOBIŃSKI W., SIEMIĄTKOWSKI J. 2006 -

Mineralizacja cynowa w środkowej części pasma łupkowego Starej Kamienicy (Sudety Zachodnie). Pr. Państw. Inst. Geol., 185: 1-136. MIKULSKI S.Z., SADŁOWSKA K., OSZCZEPALSKI S., CHMIELEWSKI A., MAŁEK R., 2018a - Weryfikacja formacji metalogenicznych w Polsce w aspekcie występowania surowców rzadkich i krytycznych. Nar. Arch. Geol. PIG-PIB, Warszawa: nr 5685/2018. MIKULSKI S.Z., OSZCZEPALSKI S., SADŁOWSKA K., CHMIELEWSKI A., MAŁEK R. 2018b - Występowanie pierwiastków towarzyszacych i krytycznych w wybranych udokumentowanych złożach rud $\mathrm{Zn}-\mathrm{Pb}, \mathrm{Cu}-\mathrm{Ag}, \mathrm{Fe}-\mathrm{Ti}-\mathrm{V}, \mathrm{Mo}-\mathrm{Cu}-\mathrm{W}, \mathrm{Sn}, \mathrm{Au}-\mathrm{As}$ i Ni w Polsce. Biul. Państw. Inst. Geol., 472: 21-52

PAULO A., KRZAK M. 2015 - Metale rzadkie. Wydaw. AGH, Kraków. SZAŁAMACHA M., SZAŁAMACHA J. 1974 - Geologiczna i petrograficzna charakterystyka łupków mineralizowanych kasyterytem na przykładzie kamieniołomu w Krobicy. Biul. Państw. Inst. Geol., 279: $59-89$.

TAYLOR S.R. 1964 - Abundance of chemical elements in the continental crust: a new table. Geochim. Cosmochim. Acta, 28: 1273-1285.

WISZNIEWSKA J. 1984 - Geneza okruszcowania łupków izerskich pasma kamienickiego. Arch. Miner., 40 (1): 115-188. 